\title{
Nanotechnology in Development of Vital Engeniring Projects (Introductory Course for the Preparation of Bachelors, Masters and Specialists in Nanotechnology)
}

\author{
Lev Nikolaevich Patrikeev ${ }^{1}$, Nikolay Ivanovich Kargin ${ }^{2}$ \\ ${ }^{1}$ Department of Micro and Nanoelectronics, National Research Nuclear University MEPhI, Moscow, Russia \\ ${ }^{2}$ Institute of Nanotechnology in Electronics, Photonics and Spintronics, National Research Nuclear University MEPhI, Moscow, Russia
}

\section{Email address:}

lnp@mail.ru (L. N. Patrikeev), nikargin@mephi.com (N. I. Kargin)

\section{To cite this article:}

Lev Nikolaevich Patrikeev, Nikolay Ivanovich Kargin. Nanotechnology in Development of Vital Engeniring Projects (Introductory Course for the Preparation of Bachelors, Masters and Specialists in Nanotechnology). Communications. Vol. 8, No. 2, 2020, pp. 28-31.

doi: $10.11648 /$ j.com. 20200802.11

Received: March 25, 2019; Accepted: February 17, 2020; Published: December 28, 2020

\begin{abstract}
This article is devoted to the introductory course program for students of any technical and humanitarian specialties. This course provides examples of the implementation of modern nano -and biotechnologies in the most important modern engineering projects. Any methodical work intended for the student, its global goal is to encourage students to their own active work. Naturally, the scientific and prospective applied interests of each student are exclusively individual. We hope that this work will help our students choose the right guidelines and look at the possibilities of nanotechnology in the implementation of the most common engineering projects. There are only a few such projects called national projects in Russia: road construction, housing construction, medical projects, food projects, defense projects, etc. Each student of the proposed introductory course is obliged to choose the subject of their abstract work and must provide the appropriate report (15-20 pages). Our experience shows that students are happy to perform such tasks and almost every second after completing the course publishes a small scientific article. At least 14 of the 24 students who took this course in the 2018-2019 academic year have written interesting articles (6 of which have already been published, and the rest have been sent to various publishers). The subjects of these 14 papers are very broad and non-standard from mathematics and Biomedicine to solar cells and graphene oxides.
\end{abstract}

Keywords: Nanotechnologies, Food Supply, Civil and Military Technology, Biomedicine, Nanostructure Research Methods, Nanomaterials Properties, Nanocomposites, Energy, Renewable Energy, Ecology, Waste Processing, Etc

\section{Introduction}

Nowadays, more than in 56 high school students are trained in numerous areas of nanotechnology. [1] The fund of infrastructure and educational programs jointly with employers approved dozens of professional standards, which are a guide for universities in the training of specialists in demand. Accredited professional programs in the areas of training are characterized by the following distribution: electronics and Nano electronics - 8 programs, photonics, optics and optoinformatics - 5, materials science and materials technology - 4, standardization and metrology - 4, microsystem technology - 2, instrument engineering - 2, construction - 1 .

In the resolution of the Government of the Russian
Federation No. 682 of 15.06.2018 "On approval of the Regulation on the Ministry of Science and Higher Education of the Russian Federation" in paragraphs 4.3.3 and 4.3.15, the monitoring of the potential of universities in the field of nanotechnology and the formation of a tool-tool for the IT development base are highlighted as the most important tasks of the Ministry.

This distribution is completely correlated with the rating of the most popular professions (according to the data of the State Committee for Statistics of 2018): 1. engineers, 2. IT specialists, 3. specialists in nanotechnology, 4. specialists combining electronics and biotechnology, 5. marketing specialists, 6. specialists in areas of service, 7. logistics, 8. environmentalists, 9. medical workers, 10. chemists. Every teacher and student should be guided by modern requirements 
for a specialist-nanotechnology and General problems of ensuring the life of mankind. [2, 3].

Long-term pedagogical experience in teaching various nanotechnology disciplines included in the curricula of MIPHI, MEI and RUDN, organizing and participating in numerous schools-seminars and conferences on the upgrading of the qualifications of masters, specialists and graduate students increasingly convince me that it is advisable to start preparing students for any nano-direction with an introductory course, which can be called as "Nanotechnology in the development of critical engineering projects".

\section{Current Situation}

\subsection{Engineering Projects}

In the 21 st century, any engineering projects and methods of managing them are improved due to the wide application of information and nanotechnology. In turn, IT is developed through the use of nanotechnology. In modern conditions, the economic efficiency of any production is based on the professional engineering activities of specialists. [4-11]

Today the country needs engineers for any specialties. No matter whomever will be trained in a particular university for nanospecialities, they should start with the introduction of students into the world of practically significant engineering projects implemented in this or that region.

\subsection{Graduates Specificity}

The mentioned statements find a convincing confirmation in the practice of industry requirements for graduates of universities. Each of the state corporations and branch state enterprises (Rostekh, Rosatom, Luxmosmos, Rosnano, RusHydro, Sovkomflot, Alrosa, etc.) require their subordinate universities to prepare specialists for programs that have not only industry specificity, but also regional peculiarities. These requirements relate primarily to programs in physics, mathematics, chemistry, biology and sociology, and naturally apply to programs on special subjects. The listed features of today are confirmed, in particular, by the practice of the publisher "Binom, Laboratory of Knowledge", with whom Lev Patrikeev has been cooperating with for many years on a voluntary basis. The preparation of graduates of any university cannot be based on the richest engineering and design domestic and world experience. That experience is continuously replenished and expanded with regard to energy, information and industrial (including civil and special), transport, medical, environmental and other engineering projects and topics.

\subsection{Industry Requirements}

All mentioned circumstances are strongly recommended to familiarize bachelors, masters and specialists with the main Russian engineering projects and their rapid development since the 12th century and on perspective - at least until the end of the 21 st century. Such familiarity will allow students from the very beginning of mastering the chosen specialty and freely navigate in modern life and consciously prepare for their professional activities. $[5,14,15]$

\section{Program}

Before proceeding to the discussion of the approximate program of the above-mentioned introductory course, we note the results of a collective analysis of the final requirements for nanotechnology graduates reflected in the work "What Every Bachelor, Master and Nanotechnology Specialist should know."[2] Numerous discussions on the requirements for the training of graduates in nanotechnology allowed participants of the all-Russian scientific seminar of NIAU MIPHI - the Nano technological Society of Russia allocated "only" 11 blocks of fundamental training, which each of them must master.

a) The world we live in and its social characteristics. [5]

b) Size effects.

c) Methods for studying nanostructures. [6, 14]

d) Basic technologies of Nano electronics.

e) Nanomaterials and nanotechnologies in living systems. $[8,9]$

f) Nanomaterials (gravel, nanotubes, diamond, graphene, fullerenes, etc.) $[2,12]$

g) Methods for obtaining Nano objects.

h) Nano goods civil applications (medicine, agriculture, food, consumer goods, construction, energy) [15]

i) Work programs of the USA, Europe and other countries.

j) Military applications of nanotechnology.

k) The frames of the Nano industry at the nearest 25, 50 and further years.

According to the collective opinion of the Nobel Prize laureates, among the most important applied engineering projects in the 21 st century are:

Energy and electrification, 2. Atomic project, 3. Wind and solar energy, 4. Railways and machine building, 5. Aviation and space projects, 6. Robotics, 7. Food project, 8 . Medicine and ecology, 9. Fighting with terrorism, 10. Social projects (informatization, education, culture).

It is the analysis of the effective influence of nanotechnologies on these projects that the pedagogical process should be supplemented with the course "Nanotechnologies in the development of Russia's most important engineering projects". The main goal of this discipline is to fully awaken students to self-familiarization with domestic engineering projects based on the use of fundamental thematic and constructive-innovative achievements of modern science-intensive technologies.

The most important task of the pedagogical process for the training of engineers of any profile is the task of forming in students an active motivational component in the development of nanotechnology. Only on the basis of such a component the desire for self-mastery of the methods and practice of this direction of modern digital information can be evolved.

Another important goal is to help and assist students in expanding their knowledge about the world around them and in 
social and literate orientation in it. Finally, another task of this course, it seems to me, is to teach students practical skills in the search and analysis of literary tempers, writing abstracts, preparing presentations, reports and articles. At the same time, considerable attention should be given to teaching students literate performance with oral messages. Naturally, the last tasks concern, in the main, work at seminars and in laboratories.

In each university, based on real conditions, the curriculum for such an introductory course can differ substantially from the example that we will give below. As an example, we will present a draft curriculum that is consistent with the leadership of all the departments included in the Institute of Nanotechnologies of the NIAU MIPHI, and in parallel all the departments that are part of the RUDN Engineering Academy.

First, let's designate the approximate volume and laboriousness of the discipline in question. Total labor intensity is 192 hours, including 96 hours of classroom and independent work of students (lectures- 48 hours, seminars-16 hours, laboratory work-18 hours, course design-14 hours.)

Secondly, we will briefly outline the content of 16 three-hour lectures of the proposed course:

1. Introduction. Modern world and its most important engineering projects. Division of markets for production and consumption of the product of advanced high technology.

2. Bioengineering. Inorganic and organic chemistry. Genomics and editing. Examples of introducing bioengineering into engineering projects.

3. MEMS - technologies. Basic technological operations of silicon nanoelectronics. Technological union of mechanical control systems with semiconductor logic elementae (.....)

4. Nanotechnology. CNT, fullerenes, graphene. Distinctive properties of nanomaterials, methods of their creation and metrics. Nanocomposites and nanocatalysts. Examples of implementation in engineering projects.

5. Remote education. Informatization and self-study. Development of the necessary content. Temporal and informative efficiency of distance education.

6. Power and electrification. Methods and levels of energy generation, efficiency and environmental friendliness. Examples of the development of engineering projects under the influence of nanotechnology.

7. Atomic project. V. I. Vernadsky, I. V. Stalin, L. P. Beria, RAS and Rosatom. Types of nuclear power plants and prospects for nuclear energy. Nanotechnology in the nuclear project.

8. Wind and solar power. History, current state and prospects of renewable energy.

9. Russian Railways. Modern transport logistics and competition. Problems of efficiency, reliability and safety. Examples of active implementation of scientific developments.

10. Mechanical engineering (including electronic industry). Cluster technological equipment, production robotization. Sharp increase in productivity, staff reduction and increased environmental requirements.

11. Aviation project. Increase in speed, carrying capacity, safety and lowering the cost of transportation. Broad introduction of nanocomposite materials and digital technologies at all stages of airplane projects.

12. Rocket and space project. The development of near-Earth space, the Moon, Mars and other planets. Nanotechnology in the development of rocket and space projects.

13. Robo-technology. Artificial intelligence, MEMS systems and the gradual replacement of people at all (primarily traumatic and harmful) production. Bio controlled prostheses, chipitization of people and animals. Ethical problems of human-machine interaction.

14. Food program. The role of computer science and nanotechnology in the improvement of crop production, poultry, fish and livestock. Problems of desalination and purification of drinking water.

15. Medicine and ecology. Necessary to form not only the methods of care, but also dramatically change the system of higher medical education and teach doctors to widespread use of digital, diagnostic and prosthetic applications.

16. The fight against terrorism. In the arsenal of states-fighters with various forms of terrorism, there are already effective IT tools exist (nanos, nanoscale, nanopinets, etc.). The park of such highly sensitive devices is constantly growing.

In the scientific and prognostic literature, in recent years, there have appeared all the new well-founded assumptions about the introduction of IT instrumentation into our daily life (R. Kuzzweil. The Singularity is near: When humans transcend biology / Viking 2005). For example, in 2016, this specialist brings such a list of expected implementations [16]:

2020 year. Personal computers will achieve computing power comparable to the human brain.

2024 year. Elements of computer intelligence will become mandatory in the automotive industry.

2030 year. The flowering of nanotechnology and industry will lead to a significant reduction in the cost of production of all products.

2037 year. There will be a giant breakthrough in understanding the mystery of the human brain.

2041 year. The maximum bandwidth of the Internet will be 500 million times more than today.

2045 year. The earth will turn into one giant supercomputer.

Of course, every region of the country may have its own specific theme. Probably you can reduce the number of lectures to 7-8. However disclose an active role in the NT era IT industry is impossible.

\section{Acknowledgements}

Nanotechnology is the science and technology of modern society; it concerns all spheres of human life. Therefore, we hope that this work will help both teachers and students in 
choosing an individual interest in using the achievements of nanotechnology in their professional activities.

This program of the introductory course offered by us is distributed by the author among the students of the all-Russian scientific seminar of the NIAU MIPHI-NOR and can be sent to any interested institution by e-mail. The request can be sent tolnp70@mail.ru.

\section{References}

[1] Technologies of new generations - M. Fund of infrastructure and educational programs. Group Rosnano. 2016.

[2] L. N. Patrikeev - "What every bachelor, master and specialist in nanotechnology should know. Sensors and systems", Number 6, 2016.

[3] "Humanity's Top Ten problems for next 50 years." Source: MIT forum 2003

[4] I. P. Stepanenko. "Basics of microelectronics". - M. Binom 202-2008.

[5] N. Kobayashi. "Introduction to nanotechnology." / Translation from Japanese A. V. Hochayan under the editorship of L. N. Patrikeev. M: Beenom, 200.

[6] V. A. Bykov. Instrument making for nanotechnology. Nanoindustry. p. 1-58, Special Issue, 2010.

[7] V. V. Starostin. "Materials and methods of nanotechnology", under the general editorship of Professor L. N. Patrikeev.
[8] A. Yu. Godymchuk, G. G. Saveliev, A. P. Zykova. "Ecology of nanomaterials", under the editorship of L. N. Patrikeev and A. A. Rivina - M.: Binom, 2012.

[9] Henry Ehrlich. "Small objects are great ideas." Under the editorship of Professor L. N. Patrikeev -M: Bean, 2011.

[10] L. N. Patrikeev - Problems of education in the field of Nanotechnology. International Journal of Nanotechnology. Vol. 15. № 4/5. 2018, 347-351.

[11] L. N. Patrikeev - Teaching nanotechnology for foreign engineering students. International Geopolitical Congress "Global Security and Scientific-technical Progress". M. 2019, № 63 .

[12] V. A. Bykov - Instumentation for the control of materials, the environment - Russia's contribution to the development of technology. International Geopolitical Congress "Global Security and Scientific-technical Progress”. M. 2019, № 62.

[13] A. Y. Khavkin - The role of oil and gas nanotechnologies in the global security of Russia and the world. International Geopolitical Congress "Global Security and Scientific-technical Progress”. M. 2019, № 62.

[14] A. Potemkin.” Solo Mono" - M.: ID Threshold, 2018.

[15] A. Potemkin EuRICAA "The model of peaceful future" - M.: ID Threshold, 2018.

[16] R. Kuzzweil. "The Singularity is near: When humans transcend biology." Viking 2005. 